\title{
Detection of Campylobacter jejuni among Commercial Broiler Chickens in East-Coast Malaysia
}

\author{
Che Mohd Noor Nur-Aziera-Aina ${ }^{1}$, Nur-Syafiqah Mohd Nasir ${ }^{2}$ and Abdul-Rahman Zaidah, ${ }^{2,}$ \\ ${ }^{I}$ Faculty of Applied Sciences, Universiti Teknologi Mara, 40450 Shah Alam, Selangor, Malaysia. \\ ${ }^{2}$ Department of Medical Microbiology \& Parasitology, School of Medical Sciences, Universiti Sains Malaysia, Kubang Kerian, 16150 Kelantan, Malaysia. \\ ${ }^{3}$ Hospital USM, Health Campus, USM, 16150, Kubang Kerian, Kelantan, Malaysia \\ *Corresponding author's Email: drzaidah@usm.my; ORCID: 0000-0002-6612-8360
}

Received: 29 Mar. 2020

Accepted: 10 May 2020

\begin{abstract}
Human campylobacteriosis is associated with contaminated foods and drinks or direct contact with the source of organisms. Broilers are the main reservoir of Campylobacter as well as the primary source of meat in many countries. The microorganism load in broilers is converted into the rate of food-related campylobacteriosis. The present study aimed to determine the Campylobacter jejuni colonization load in commercial broiler chickens in east coast Malaysia. Cloaca swabs were taken after consent from the owners of selected broiler farms in Kelantan, Malaysia. Swabs were kept in Amie's transport media before being placed in enrichment broth. The DNA was extracted directly from the broth and specific Polymerase Chain Reaction (PCR) was performed, which targeted hippurate hydrolase (hipO) gene of $C$. jejuni. Three broiler farms from different districts in Kelantan were identified. A total of 120 cloacal swabs were analyzed, 20\% (24/120) confirmed by PCR-positive for hipO gene when the amplified product with the band size of approximately 344 bases per was visualized on agarose gel. It is concluded that the prevalence of $C$. jejuni colonization among living broiler flocks in Kelantan was at a low level. However, further studies with bigger sample size and involvement of more farms are needed.
\end{abstract}

Key words: Broiler chicken, Campylobacter jejuni, Cloaca swab, Polymerase Chain Reaction, Hippurate hydrolase

\section{INTRODUCTION}

More than 30 Campylobacter species has been identified to date (Pitkanen and Hanninen, 2017). However, Campylobacter jejuni and Campylobacter coli are the two predominant species that cause gastrointestinal infections, based on analysis of 1020 inflammatory stool samples (Ranjbar et al., 2017). The person acquired the infection after consuming contaminated food or water or after having direct contact with the source. Since the 1970s, the broiler has been the main cause of campylobacteriosis, which has been identified in connection with human nutrition. The presence of high Campylobacter rate in broiler chickens and their carcasses is one of the major risk factors for human acquisition (Marotta et al., 2015; Skarp et al., 2016).

Broiler chickens, specifically Gallus gallus domesticus, have a significant contribution to meat production worldwide (Skarp et al., 2016). It was estimated that around 20 to $30 \%$ of campylobacteriosis in the European Union was related to chicken meat consumption, as reported by European Food Safety Authority. Another report indicated 50-80\% infections might be attributed to the entire chicken reservoir. It is also emphasized that consumption of broiler meat production contributed to campylobacteriosis in different regions (Skarp et al., 2016; Ranjbar and Babazadeh, 2017).

There are limited reports on Campylobacter species in living broiler chickens. Furthermore, no data are available for the Kelantan District, where the study is being conducted. To reduce the incidence of campylobacteriosis in human, understanding the colonization status or contamination of poultry by Campylobacter species is very necessary for intervention strategies and monitoring programs in the primary broiler production chain. Thus, the aim of this study was to 
determine the colonization load of $C$. jejuni, which is the predominant species in local broiler farms.

\section{MATERIALS AND METHODS}

\section{Ethical approval}

The study was approved by the Institutional Animal Care and Use Committee of the Universiti Sains Malaysia (USM) (USM/IACUC/2018/ 113, 928).

\section{Sample collection}

Three commercial broiler chicken farms were identified in the three locations in Kelantan state on the east-coast Malaysia. The farms had about 2000 to 6000 broiler each. One hundred cloacal samples were taken from the first two farms (50 samples from each farm) and another 20 samples were taken from the last farm. The samples were taken according to the availability of the broiler during sampling and with consent of owners. The samples were taken using a moistened sterile cotton swabs and immediately kept in Amie's transport medium. Within 1-2 hours, the swabs were placed in $3 \mathrm{~mL}$ of Blood Free Campylobacter broth (Oxoid, France) and incubated at $37^{\circ} \mathrm{C}$ for 48 hours to enhance Campylobacter growth.

\section{PCR}

The DNA extraction was performed using a boiling lysis method directly from the broth according to the published protocols with modifications (Singh et al., 2011). The boiling method is a classic alternative procedure of DNA extraction using TE buffer to lyse the cells, followed by rapid boiling at $95^{\circ} \mathrm{C}$ to obtain the DNA. About $100 \mu \mathrm{L}$ of broth was mixed with $100 \mu \mathrm{L}$ of sterile distilled water and centrifuged at 10,000 rounds per minute (rpm) for three minutes. The supernatant was removed, and the remained pellets were suspended again with $100 \mu \mathrm{L}$ TE buffer. The samples were vortexed to mix them up and boiled at $95^{\circ} \mathrm{C}$ for 10 minutes to lyse the bacteria cells. The samples were centrifuged again at $10,000 \mathrm{rpm}$ for three minutes. The supernatant was used directly as a template in a PCR reaction. A set of specific forward (5'-GAC TTC GTG CAG ATA TGG ATG CTT3') and reverse (5'-GCT ATA ACT ATC CGA AGA AGC CAT CA-3') primers were used, targeting hippurate hydrolase (hipO) gene characteristic of $C$. jejuni. The primers were proved to be specific for $C$. jejuni (Persson and Olsen, 2005). The conventional PCR was performed in a total reaction volume of $25 \mu \mathrm{L}$ containing $12.5 \mu \mathrm{L}$ of $2 \mathrm{x}$ PCR buffers, $4.3 \mu \mathrm{L}$ of PCR water, $1.6 \mu \mathrm{L}$ of $5 \mu \mathrm{M}$ of forward and reverse primers respectively and $5 \mu \mathrm{L}$ of extracted DNA, which served as template DNA. The reactions prepared were run in the thermocycler with an initial denaturation of 6 minutes at $94^{\circ} \mathrm{C}$ followed by 35 cycles of $94^{\circ} \mathrm{C}$ (50 seconds), $57^{\circ} \mathrm{C}$ (40 seconds) of annealing, and $72^{\circ} \mathrm{C}$ (50 seconds) extension with a final extension at $72^{\circ} \mathrm{C}$ for 3 minutes. The Polymerase Chain Reaction (PCR) products were analyzed on $1.5 \%$ agarose gel and a fragment with a size of 344 base per (bp) was identified as hipO gene.

\section{RESULTS AND DISCUSSION}

The PCR was considered positive for hipO gene when the amplified product with the band size of approximately 344 bp was visualized on agarose gel. A total of 120 cloaca swabs were taken and analyzed. Twenty-four (20\%) samples were positive. A representative of the PCR analysis as shown in figure 1. C. jejuni was regarded as an intestinal flora of chickens but was recognized to cause campylobacteriosis in humans. Many researches were conducted to correlate the occurrence of the organism with the contamination and infection of human food (Skarp et al., 2016). The contamination was linked with the various stages of chicken meat production and processing chain until the consumption of chicken meat in the community. The production chain of chicken meat varied between regions, industrialized and developing countries. This would determine the contamination rate during the processes. The Campylobacter contamination in poultry farms subsequently reflected the contamination rate of carcasses and meat (Kaakoush et al., 2015; Skarp et al., 2016). In the recent study, the PCR was able to detect 24 (20\%) positive samples among the living broilers compared to the previous data from Thailand, in which the prevalence of Campylobacter species in broilers ceca was reported $11.2 \%$ and 11 out of 98 ceca samples taken in the slaughterhouse were positive by culture method (Chokboonmongkol et al., 2013). Researchers postulated that the prevalence after avian influenza outbreaks declined drastically in 2004, with strict biosecurity measures in the broiler farms and the administration of antimicrobials were implemented to chickens less than 3 days old. Another study in 2017 showed a high prevalence and isolation rate around 40-60\%, depend on the region and climate during the sampling (Prachantasena et al., 2017). A higher isolation rate was noted in Ecuador when the study was conducted from 2013 to 2014. About 64 to $70 \%$ Campylobacter species were isolated from ceca in the slaughterhouse. The chickens usually came from one identified breeding farm, but from different batches 
(Vinueza-Burgos et al., 2017). Another high isolation rate was reported from Austria in 2015 and during the study of 15 broiler flocks, 80\% ( $\mathrm{n}=12 / 15)$ were positive for Campylobacter species by some detection methods. At least samples were positive by one of the detection methods (lateral flow, direct plating, Bolton broth enrichment and real-time PCR). C. jejuni was detected as predominant species in poultry flocks (Schallegger et al., 2015). A study in the United Kingdom noted the Campylobacter species being colonized at the slaughterhouse and the prevalence was almost $95.9 \%$. However, the methods of detection influenced the outcome of the study (Rodgers et al., 2017).

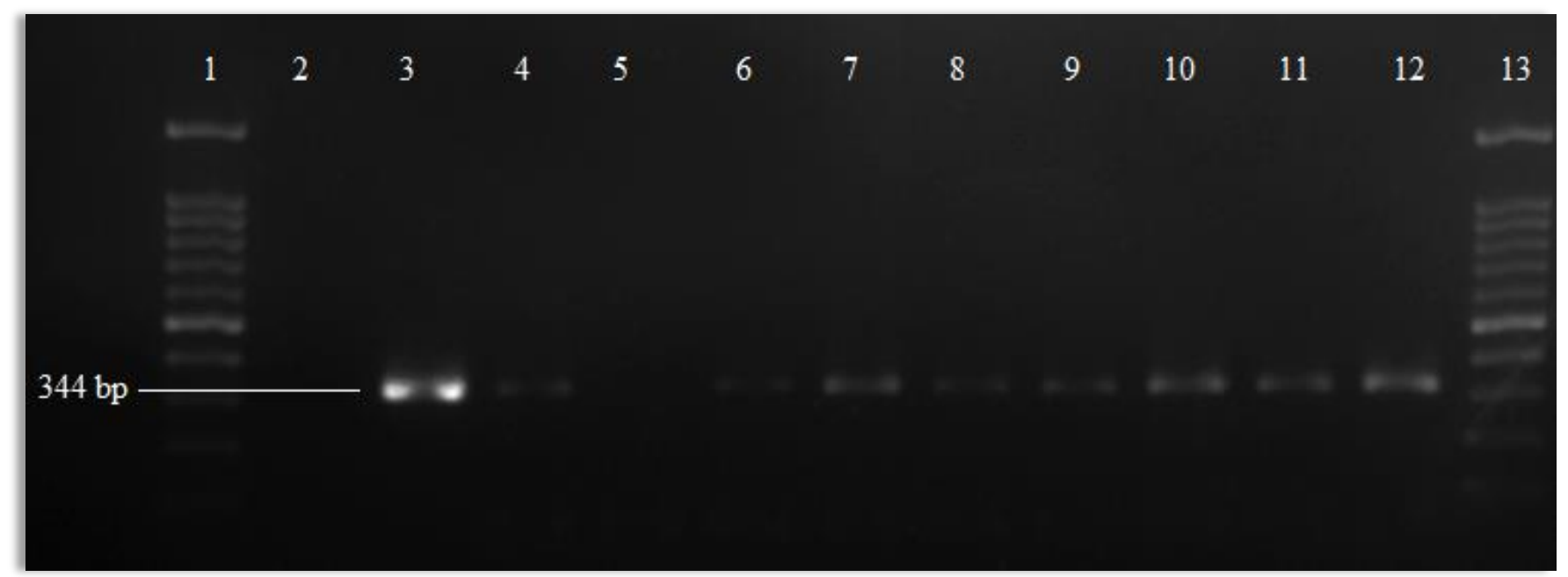

Figure 1. Conventional PCR analysis of hipO gene from broilers in east-coast region of Malaysia. Lanes 1 and 13: DNA Ladder (100 bp); Lane 2: Negative control; Lane 3: Positive control (344bp); Lanes 4-12: Cloaca samples (Lane 4 and Lanes 6-12: Positive; Lane 5: Negative)

\section{CONCLUSION}

It is concluded that the colonization load of $C$. jejuni in local broiler farms is still low in study locations compared to other reports. However, further studies with larger sample sizes and involvement of more farms in different locations are very necessary. There is a lot of routs for improvement in order to prevent human campylobacteriosis. The control and prevention program requires a multidisciplinary approach that includes both food-chain production and the consumer as the end-users. Regular monitoring of Campylobacter species load in commercial broiler chickens is necessary for successful control of human campylobacteriosis in connection with meat production.

\section{DECLARATIONS}

\section{Acknowledgements}

The investigators acknowledge the RUI grant (Grant number 1001/PPSP/8012259) from Universiti Sains Malaysia for the financial support of this project. We also thank the veterinary staff of Districts of Kelantan for their assistance and the farm owners for their consented sampling.

\section{Competing interests}

The authors have declared that no competing interest exists.

\section{Authors' contributions}

Nur-Aziera-Aina CMN had performed the fieldwork, laboratory analysis and drafting the manuscript. Nur-Syafiqah MN had also performed the field-work and laboratory analysis, and Zaidah AR supervised the fieldwork, monitored the laboratory analysis, drafted the manuscript. All authors approved the final revised manuscript.

\section{REFERENCES}

Chokboonmongkol C, Patchanee P, Gölz G, Zessin KHR and Alter T (2013). Prevalence, quantitative load, and antimicrobial resistance of Campylobacter spp. from broiler ceca and broiler skin samples in Thailand. Poultry Science, 92: 462-467. DOI: https://doi.org/10.3382/ps.2012-02599

Kaakoush NO, Castaño-Rodríguez N, Mitchell HM and Man SM (2015). Global epidemiology of Campylobacter infection. Clinical 
Microbiology Review, 28(3): $687-720 . \quad$ DOI: https://doi.org/10.1128/CMR.00006-15.

Marotta F, Garofolo G, Donato GD, Aprea G, Platone I, Cianciavicchia S, Alessiani A and Giannatale ED (2015). Population diversity of Campylobacter jejuni in poultry and its dynamic of contamination in chicken meat. BioMed Research International, Volume 2015: Article ID 859845, pp. 1-10. DOI: https://doi.org/10.1155/2015/859845

Persson S and Olsen KE (2005). Multiplex PCR for identification of Campylobacter coli and Campylobacter jejuni from pure cultures and directly on stool samples. Journal of Medical Microbiology, 54: 1043-1047. DOI: https://doi.org/10.1099/jmm.0.46203-0

Pitkanen T and Hanninen M-L (2017). Members of the family Campylobacteraceae: Campylobacter jejuni, Campylobacter coli. In: J.B. Rose and B. Jiménez-Cisneros, (eds) Global Water Pathogen Project. (A. Pruden, N. Ashbolt and J. Miller (eds) Part 3 Bacteria). Available at: https://www.waterpathogens.org/book/campylobacter

Prachantasena S, Charununtakorn P, Muangnoicharoen S, Hankla L, Techawal N, Chaveerach P, Tuitemwong P, Chokesajjawatee N, Williams $\mathrm{N}$ and Humphrey $\mathrm{T}$ et al. (2017). Climatic factors and prevalence of Campylobacter in commercial broiler flocks in Thailand. Poultry Science, 96: 980-985. DOI: https://doi.org/10.3382/ps/pew364

Ranjbar R, Babazadeh D and Jonaidi-Jafari N (2017). Prevalence of campylobacter jejuni in adult patients with inflammatory bacterial diarrhea, East Azerbaijan, Iran. Acta Medica Mediterranea, 33: 901. Available at: http://www.actamedicamediterranea.com/archive/2017/specialissue-1/prevalence-of-campylobacter-jejuni-in-adult-patients-withinflammatory-bacte-rial-diarrhea-east-azerbaijan-iran
Ranjbar R and Babazadeh D (2017). Contact with poultry and animals increases risk of Campylobacter infections in adults of Ardabil province, Iran. Universa Medicina, 36(1): 59-67. DOI: http://dx.doi.org/10.18051/UnivMed.2017.v36.59-67

Rodgers JD, Simpkin E, Lee R, Clifton-Hadley FA and Vidal AB (2017). Sensitivity of direct culture, enrichment and pcr for detection of campylobacter jejuni and c. coli in broiler flocks at slaughter. zoonoses public health, 64(4): 262-271. DOI: https://doi.org/10.1111/zph.12306

Schallegger G, Muri-Klinger S, Brugger K, Lindhardt C, John L, Glatzl M, Wagner M and Stessl B (2016). Combined Campylobacter jejuni and Campylobacter coli Rapid Testing and Molecular Epidemiology in Conventional Broiler Flocks. Zoonoses Public Health, 63(8): 588-599. DOI: https://doi.org/10.1111/zph.12267

Singh H, Rathore RS, Singh S and Cheema PS (2011). Comparative analysis of cultural isolation and PCR based assay for detection of Campylobacter jejuni in food and fecal samples. Brazilian Journal of Microbiology, 42(1): 181-186. DOI: https://doi.org/10.1590/S1517-83822011000100022

Skarp CPA, Hänninen ML and Rautelin HIK (2016). Campylobacteriosis: the role of poultry meat. Clinical Microbiology and Infection, 22: 103-109. DOI: https://doi.org/10.1016/j.cmi.2015.11.019

Vinueza-Burgos C, Wautier M, Martiny D, Cisneros M, Damme IV and Zutter LD (2017). Prevalence, antimicrobial resistance and genetic diversity of Campylobacter coli and Campylobacter jejuni in Ecuadorian broilers at slaughter age. Poultry Science, 96: 23662374. DOI: https://doi.org/10.3382/ps/pew487 